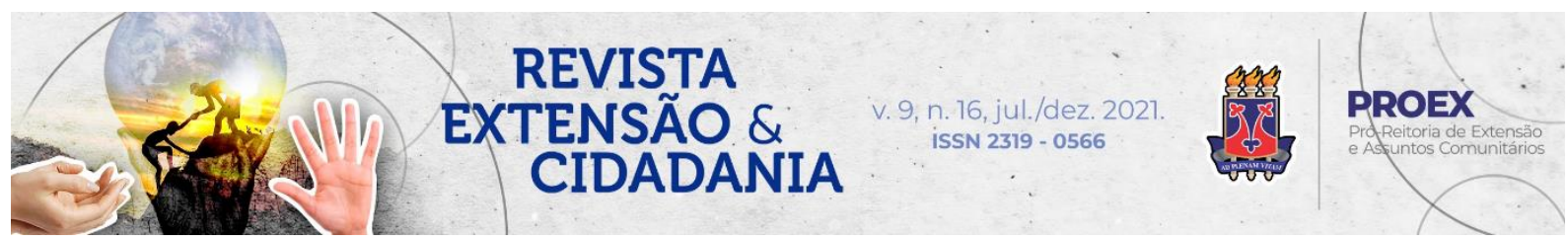

DOI: $10.22481 /$ recuesb.v9i16.8671

\title{
AÇÕES EXTENSIONISTAS DO GEPAN: INTERDISCIPLINARIDADE E ABRANGÊNCIA
}

\section{EXTENSIONIST ACTIONS BY GEPAN: INTERDISCIPLINARITY AND SCOPE}

\author{
ACCIONES EXTENSIONISTAS DEL GEPAN: INTERDISCIPLINARIEDAD Y \\ ALCANCE
}

\author{
Amanda Carla Oliveira ${ }^{1}$ \\ Ana Lúcia Castilhano de Araújo ${ }^{2}$ \\ Edisio Pereira da Silva Luz Júnior ${ }^{3}$ \\ Felipe Santos Viana ${ }^{4}$ \\ Grazielle Meira Freire ${ }^{5}$ \\ Mariana Batista de Moraes ${ }^{6}$
}

Resumo: O presente artigo aborda acerca das ações extensionistas do Grupo de Estudos em Psicologia Analítica, que desde 2019 atua através do projeto de extensão Estudos de Psicologia Analítica da Universidade Estadual do Sudoeste da Bahia, e promove espaços de estudo e divulgação da psicologia de Carl Gustav Jung. Objetivando destacar o caráter interdisciplinar do grupo de estudos e do projeto de extensão, através de um relato de experiência, este artigo discorre a respeito da abrangência da citada atividade extensionista e da ampliação de seu alcance com a utilização das redes sociais, principalmente com a aderência às modalidades virtuais em decorrência da pandemia da Covid-19. São debatidos resultados como: encontros criativos, minicursos, submissão de resumos no $9^{\circ}$ Congresso Brasileiro de Extensão Universitária, além da ampliação da participação comunitária no projeto após o rompimento das barreiras geográficas, proporcionado pela adesão às plataformas virtuais. Finalmente,

\footnotetext{
${ }^{1}$ Graduanda em Psicologia, pela Universidade Estadual do Sudoeste da Bahia (UESB), Vitória da Conquista, Bahia, Brasil. Orcid: https://orcid.org/0000-0002-5499-2979 E-mail: amandacarloliv@ gmail.com

2 Psicóloga. Doutora em Educação. Professora da Universidade Estadual do Sudoeste da Bahia (UESB), Vitória da Conquista, Bahia, Brasil. Orcid: https://orcid.org/0000-0003-3554-828X E-mail: alcastilhano@uesb.edu.br

${ }^{3}$ Graduando em Psicologia, pela Universidade Estadual do Sudoeste da Bahia (UESB), Vitória da Conquista, Bahia, Brasil. Membro do Núcleo de Pesquisas e Estudos em Psicologia, linha Avaliação Psicológica, Formação em Psicologia Sociedade e Saúde. Orcid: https://orcid.org/0000-0003-3670-9321 E-mail: epsljr@ gmail.com

${ }^{4}$ Graduando em Psicologia, pela Universidade Estadual do Sudoeste da Bahia (UESB), Vitória da Conquista, Bahia, Brasil. Orcid: https://orcid.org/0000-0002-7006-1509 E-mail: felipxviana@gmail.com

${ }^{5}$ Graduanda em Psicologia, pela Universidade Estadual do Sudoeste da Bahia (UESB), Vitória da Conquista, Bahia, Brasil. Orcid: https://orcid.org/0000-0003-3671-9095Ｅ-mail: graziellefreire1@gmail.com

${ }^{6}$ Graduanda em Psicologia, pela Universidade Estadual do Sudoeste da Bahia (UESB), Vitória da Conquista, Bahia, Brasil. Orcid: https://orcid.org/0000-0002-3278-1468 E-mail: mbmoraes.psicologia@ gmail.com
} 
retoma-se a importância das ações extensionistas, que funcionaram como catárticas à produção de diferentes ferramentas de aproximação da comunidade externa e de construção coletiva e multidimensional dos saberes, ações mediadas e envolvidas pelas artes e tecnologias de comunicação, expandindo as discussões para além do espaço da Psicologia.

Palavras-chave: Extensão. Interdisciplinaridade. Psicologia Analítica. Redes sociais.

Abstract: This article concerns the service activities developed by the Analytical Psychology Study Group, which has been acting since 2019 by means of the Southwest Bahia State University Analytical Psychology service project, and promotes venues for studying and popularizing the psychology of Carl Gustav Jung. Aiming to emphasize the interdisciplinarity of this study group as well as this university-service project, through an experience report, this work discourses on the coverage of the aforementioned service-based activity and on the widening of its reach by using social media, especially adhering to virtual modalities due to the Covid-19 pandemic. The results hereby discussed include: creative meetings, minicourses, the submission of manuscript abstracts to the nineth Brazilian University Service Congress, as well as the broadening of community participation into the project after geographical barriers were overcome, which provides adhesion to web platforms. Finally, it retrieves the importance of university-service actions that had functioned as cathartic to the production of diverse tools aimed at gathering external community and collective, multidimensional construction of knowledge and actions mediated and involved by arts along with communication technologies, expanding thus the discussions beyond the scope of Psychology.

Keywords: University service. Interdisciplinarity. Analytical Psychology. Social media.

Resumen: Este artículo trata de las acciones extensionistas llevadas a cabo por el Grupo de Estudios en Psicología Analítica que ha actuado desde el año 2019 por medio del proyecto de extensión "Estudios de Psicología Analítica" de la Universidad Estadual del Suroeste de Bahia. Dicho grupo promueve espacios de estudio y divulgación de la psicología de Carl Gustav Jung. Con el objetivo de destacar el carácter interdisciplinario del grupo de estudios y del proyecto de extensión al realizar un relato de experiencia, este artículo discute la cobertura de dicha actividad extensionista y la ampliación de su alcance tras el uso de redes sociales, principalmente con la adherencia a las modalidades virtuales debido a la pandemia de Covid19. Se discuten resultados tales como: encuentros creativos, minicursos, sumisión de resúmenes al $9^{\circ}$ Congreso Brasileño de Extensión Universitaria, además de la ampliación de la participación comunitaria en el proyecto tras el rompimiento de las barreras geográficas, lo que ha proporcionado adhesión a plataformas virtuales. Finalmente, retómese la importancia de las acciones extensionistas, las cuales han funcionado de manera catártica a la producción de diferentes herramientas de aproximación de la comunidad externa y de construcción colectiva y multidimensional de los saberes, acciones mediadas e involucradas por las artes y tecnologías de comunicación, expandiendo los debates más allá del espacio de la Psicología.

Palabras clave: Extensión. Interdisciplinariedad. Psicología Analítica. Redes sociales.

Revista Extensão \& Cidadania, v. 9, n. 16, p. 7-20, jul./dez. 2021.

ISSN 2319-0566 DOI: 10.22481/recuesb.v9i16.8671 


\section{Introdução}

O Projeto de Extensão Estudos de Psicologia Analítica se inicia, em 2019, a partir da vontade de docentes e discentes, especialmente do curso de Psicologia, de estudar a abordagem de Carl Gustav Jung. A importância dos estudos e da teoria junguiana vai muito além de um método de psicoterapia, abrangendo discussões filosóficas, a arte, a história por meio das mitologias, propondo um trânsito bem fundamentado entre áreas como a Psicologia, a Medicina (em particular, com os estudos em Psicotrauma e Psicossomática), o Cinema, a Literatura, a Antropologia e, especialmente, a Psiquiatria, tendo como destaque o primoroso trabalho de Nise da Silveira (SILVEIRA,1981). A Psicologia Analítica, ou Complexa, também apresenta relevância para os campos da Sociologia e estudos políticos (ODAJNYK, 2007).

Apesar de ter seguido adiante após o rompimento com Freud e a Psicanálise, Jung ainda permanece restrito quando o assunto é o meio acadêmico, sobretudo, no nível de graduação em Psicologia. Pouquíssimos cursos incluem o estudo da Psicologia Analítica de Jung em seus currículos, o que, certamente, configura uma exclusão epistemológica que restringe à discussão ampliada da Psicologia como ciência. Assim, tornam-se relevantes os esforços para inserir o pensamento de Jung no meio acadêmico. A cidade de Vitória da Conquista, na Bahia, possui atualmente cinco cursos de graduação em Psicologia, sendo dois deles oferecidos em instituições públicas. A representação da Psicologia na cidade e região tende a se tornar significativa para a Bahia e para o Brasil, dependendo de esforços integrados que podem se traduzir, inclusive em ações extensionistas que, no caso do presente Projeto, lançam o germe para o estudo científico de Jung na região sudoeste.

Jung constrói a teoria tendo como base sua experiência de longos anos em hospital psiquiátrico nos estudos filosóficos, bem como seu interesse pelos ritos e religiões em nível antropológico e histórico, a isso tudo ainda se pode acrescentar os estudos em alquimia e mitologia comparada. O autor parte de uma concepção que estende a experiência humana para além do aspecto racional, considera, como Freud, a relevância do desconhecido como parte da própria definição do que é ser humano. No entanto, vai mais além para apresentar uma dinâmica psíquica na qual impera um trabalho compensatório, a partir de uma instância inconsciente que não se define como depósito de experiências, mas como algo a priori e completo em si mesmo.

Para Jung (1991), tanto o corpo humano como a psique compartilham respectivamente uma anatomia e um tronco comum originários de épocas remotas da existência. Isso faz com

Revista Extensão \& Cidadania, v. 9, n. 16, p. 7-20, jul./dez. 2021.

ISSN 2319-0566 DOI: 10.22481/recuesb.v9i16.8671 
que os seres humanos partilhem não apenas uma determinada estrutura anatômica e fisiológica, mas também uma lógica de funcionamento psíquico que inclui um arsenal herdado, uma tendência a imagens e mitos que remontam a ancestrais muito antigos, e se manifesta de maneira intensa e misteriosa sob a forma de fantasias, sonhos, imagens e símbolos de natureza inconsciente e autônoma.

Sonu Shamdasani (2011, p. 27) afirma que para Jung, "a psicologia era a disciplina capaz de unir o círculo das ciências", referindo-se à amplitude dos assuntos discutidos no curso de sua obra. Sendo assim, tanto as diversas áreas do conhecimento podem se beneficiar de Jung, como a própria abordagem do autor propõe a compreensão das produções culturais humanas, do autoconhecimento, incluindo aspectos inconscientes, como fatores de saúde mental e individuação. De acordo com o Fórum de Pró-Reitores das Instituições Públicas de Educação Superior Brasileiras:

A Extensão Universitária denota uma postura da Universidade na sociedade em que se insere. Seu escopo é o de um processo interdisciplinar, educativo, cultural, científico e político, por meio do qual se promove uma interação que transforma não apenas a Universidade, mas também os setores sociais com os quais ela interage. (FÓRUM, 2012, p. 28)

Nesta visão, a ciência e a sociedade se alimentam mutuamente tanto no processo formal de construção do conhecimento como no progresso social que pode ser alcançado a partir de preceitos e descobertas científicas. Espera-se que, progressivamente, os participantes das ações extensionistas possam trazer propostas de discussão e aprendizagem de forma cada vez mais presentes nos conteúdos de ensino. É desta maneira que percebemos a ação indissociada entre ensino, pesquisa e extensão no projeto apresentado.

Partindo desse contexto, um dos objetivos do Projeto de Extensão Estudos em Psicologia Analítica é o de criar um estudo sistemático da psicologia de Jung, tendo a Universidade Estadual do Sudoeste da Bahia (UESB) como base, ajudando a divulgá-la no meio acadêmico e social. Como desdobramento desse objetivo geral, o projeto se propõe a colaborar de forma interdisciplinar para a formação de discentes, docentes e pessoas interessadas da comunidade para a constituição de grupos de estudos e pesquisa a médio e longo prazo tendo como campo de estudos a Psicologia Analítica. O presente estudo se propõe, através de relato de experiência, discorrer a respeito da abrangência da atividade extensionista e da ampliação

Revista Extensão \& Cidadania, v. 9, n. 16, p. 7-20, jul./dez. 2021.

ISSN 2319-0566 DOI: 10.22481/recuesb.v9i16.8671 
de seu alcance com a utilização das redes sociais, principalmente com a aderência às modalidades virtuais, em decorrência da pandemia da COVID-19.

\section{Metodologia do GEPAN}

As ações desenvolvidas durante todo o Projeto de Extensão, partindo do embasamento propiciado pelo Grupo de Estudos de Psicologia Analítica (GEPAN), grupo que também possui caráter extensionista na UESB, são de grande importância para a formação acadêmica, visto o engajamento recíproco entre o grupo favorecendo a horizontalidade das relações tanto pessoais quanto profissionais.

A ação principal do Projeto se refere ao estudo sistemático da psicologia junguiana, sendo esta realizada através do chamado Encontro de Estudos: reuniões mensais para discussão e debate de textos pré-estabelecidos em conjunto e leitura prévia individualmente. Cada encontro é divulgado através de mídias sociais e o convite é aberto para toda a comunidade, acadêmica e geral, estudiosa ou não da obra de Jung. Ao todo já foram discutidos 14 textos, escolhidos através da recomendação do Professor Mestre Heráclito Pinheiro, coordenador e professor do curso de Psicologia Junguiana, do Instituto Dédalos.

Os textos estudados e discutidos da coleção Obras Completas, de C. G. Jung, foram: A prática da Psicoterapia, vol. 16/1 (1985); Presente e futuro: Civilização e mudança, Parte I, vol. 10/1 (2011); capítulo Da Formação da Personalidade, do livro O Desenvolvimento da Personalidade, vol. 17 (2011); o capítulo Resposta a Martin Buber - o bem e o mal na psicologia analítica, do livro Escritos Diversos, vol. 11/6 (2012); os primeiros capítulos de Aion, vol. 9/2 (1990); Psicologia do Inconsciente, vol. 7/1 (2011); O Eu e o inconsciente, vol. 7/2 (2008); capítulo seis, do livro Os Arquétipos e o Inconsciente Coletivo, vol. 9/1 (2000); Tipos psicológicos, vol. 6 (1991); Fundamentos de Psicologia Analítica, vol. 18/1 (1985). Ainda do mesmo autor, também estudamos o capítulo um, do livro O homem e seus símbolos (1964). De outros autores, as obras estudadas foram: Jung: vida e obra (1981), de Nise da Silveira e A Interpretação dos Contos de Fadas (1999), de Marie-Louise von Franz.

As discussões realizadas preservam o aspecto da horizontalidade, em que todos podem e devem contribuir com a discussão, independentemente do nível de estudo em Psicologia Analítica, de ser integrante do GEPAN ou participante novato. Desta forma, preza-se o estudo em conjunto e papel ativo dos integrantes - sejam estes cotidianos ou esporádicos -, além do

Revista Extensão \& Cidadania, v. 9, n. 16, p. 7-20, jul./dez. 2021.

ISSN 2319-0566 DOI: 10.22481/recuesb.v9i16.8671 
incentivo à interdisciplinaridade, visto que todos podem contribuir, independente da sua área de formação. Inicialmente, todos os Encontros de Estudos aconteciam aos sábados de manhã, na UESB, mas devido à pandemia da Covid-19, as reuniões se dão agora por meio virtual através da plataforma de videoconferência Google Meet.

Dentre as atividades, estão os Encontros Criativos: ações extensionistas amplamente divulgadas na comunidade acadêmica e em redes sociais, iniciadas em maio de 2019, na UESB, em que obras artísticas (cinematográficas, literárias e afins) são comentadas à luz da Psicologia Analítica. O GEPAN inaugurou sua proposta com a exibição do documentário Questão do Coração (1985), apresentando a vida e obra de Jung à comunidade. Na sequência, já foram comentados mais nove longas e uma obra literária, além de serem realizados dois minicursos frutos da proposta dos Encontros Criativos e idealizados em parceria com outros grupos. A primeira colaboração se deu em setembro de 2020 com o Centro Acadêmico do curso de Psicologia (Gestão Nise da Silveira), já o mais recente minicurso foi realizado em abril de 2021 com a participação do Grupo Paideia, resultando em discussões que aliaram os temas apresentados a diversos conceitos junguianos.

Nos Encontros Criativos, o recurso mais utilizado foram as obras cinematográficas. Dessa forma, a linguagem fílmica é utilizada como base para discussão de temas da Psicologia Analítica, expandindo-a tanto dentro do espaço acadêmico, quanto para o público leigo nesta abordagem teórica. Para Monteiro (2013, p. 11), o cinema pode ser compreendido como uma projeção de nossa realidade, "mesclando a beleza da arte com os arquétipos, os simbolismos da vida, o surreal, a complexidade das relações entre as pessoas e com os meandros da emoção da alma humana". A autora também assinala que:

A arte cinematográfica com suas possibilidades quase ilimitadas de dialogar
com os espectadores, não ficou restrita ao campo de contar histórias ou de ser
apenas um elemento de entretenimento para o público. Como tela de projeção
da nossa realidade, o cinema mesclou toda a beleza da arte com os arquétipos,
os simbolismos da vida, o surreal, a complexidade das relações entre as
pessoas e com os meandros das emoções da alma humana [...]. (MONTEIRO,
2013, p. 11)

Após a exibição do primeiro documentário, as produções de longa-metragem discutidas foram respectivamente: The wall (1982); Guardião dos sonhos (2003); Sete minutos depois da meia-noite (2016); A face do outro (1966); O Babadook (2014); Kill Bill (2004); Coringa

Revista Extensão \& Cidadania, v. 9, n. 16, p. 7-20, jul./dez. 2021.

ISSN 2319-0566 DOI: 10.22481/recuesb.v9i16.8671 
(2019); Peixe grande (2004); e A ostra e o vento (1997). Sendo que a discussão das três últimas obras citadas se realizou de forma virtual, em função da pandemia de COVID-19.

A primeira experiência online desta ação extensionista, foi a edição intitulada “Aspectos Simbólicos no filme Coringa (2019)", realizada pela plataforma de videoconferência do Google Meet, em setembro de 2020, após ampla divulgação pelas mídias sociais, atraindo um público numeroso e diverso, totalizando 52 participantes. A temática contemporânea explorada pelo filme possibilitou debates bastante participativos sobre saúde mental, conflitos sociais e outras questões que remetem à atemporalidade de conceitos galgados por Jung (2000), além da articulação entre esses conceitos e o presente tempo histórico que se apresenta em suas diversas manifestações políticas, sociais e também psicológicas.

Seguindo os Encontros Criativos na modalidade online e inaugurando a discussão de uma obra literária, o GEPAN inicia a prática de extensão no ano de 2021 com o livro "O Oceano no Fim do Caminho" (2013) de Neil Gaiman, realizada também pela plataforma Google Meet. Essa edição foi guiada pela professora Ana Lúcia Castilhano, que recentemente escreveu sobre o livro no trabalho de conclusão em seu Curso de Especialização em Psicologia Analítica no Instituto Junguiano da Bahia (IJBA).

Os minicursos realizados também foram concebidos numa modalidade online, o primeiro deles, "Mitos e Arquétipos nos Animes dos Estúdios Ghibli”, se deu em sinergia com o Centro Acadêmico de Psicologia, ocorrendo durante o $1^{\circ}$ Ciclo de Minicursos da Gestão Nise da Silveira. O evento, em comemoração ao Dia da Psicóloga, objetivava uma discussão, durante os meses de setembro e outubro, acerca das diversas áreas de atuação e estudo da psicologia, sendo deste modo o GEPAN convidado para apresentar-se como extensão e grupo de estudos num diálogo analítico e antropológico, com o também convidado Prof. Dr. José Ricardo Marques (UESB), acerca dos mitos e arquétipos presentes na arte cinematográfica dos animes, do Studio Ghibli. Como resultado de sugestões recebidas dos participantes do primeiro minicurso, o mais recente minicurso, “Arquétipos Sem Fim: os perpétuos de Gaiman e os conceitos de Jung", propôs uma análise junguiana dos Perpétuos, personagens da história em quadrinhos (HQ) "Sandman", de Neil Gaiman, e teve como palestrante o Prof. Me. Claudiney Moreira Mendonça da Universidade Federal do Ceará (UFC) e do Grupo Paideia.

Cada Encontro Criativo e Minicurso realizado possibilitou inúmeras trocas de conhecimento e experiência entre as pessoas que participam, sejam elas do meio acadêmico ou da comunidade externa, do mesmo município ou de outros estados durante o período de

Revista Extensão \& Cidadania, v. 9, n. 16, p. 7-20, jul./dez. 2021.

ISSN 2319-0566 DOI: 10.22481/recuesb.v9i16.8671 
pandemia ainda vigente, trocas estas permeadas de vivências riquíssimas como só a arte é capaz de despertar. Desde então, as ações desenvolvidas pelo grupo vêm aproximando cada vez mais pessoas interessadas tanto nas concepções teóricas que embasam o projeto, quanto nas temáticas abordadas pelas diversas produções artísticas, agregando tais participantes ao GEPAN em suas atividades de extensão e também de estudo.

\section{Resultados e discussões: o impacto das ações extensionistas}

O Instagram como ferramenta de divulgação e comunicação

O avanço das tecnologias de comunicação, segundo Moran (1995), tem permitido usar os diversos sentidos e compartilhar diferentes experiências na realidade e no mundo virtual. Consequentemente, esses avanços têm modificado também a relação pedagógica, tanto no sentido de reforçar visões tradicionais de educação, quanto de abrir caminhos para novos jeitos de educar, de partilhar conhecimento (MORAN, 1995).

Atentando-se aos múltiplos usos e benefícios comunicacionais que as redes poderiam permitir ao Projeto, como a divulgação das ações do GEPAN, foi criada uma página para o grupo na rede social Instagram, além do grupo no WhatsApp. A função da página é a de divulgar tanto os encontros do grupo nos quais acontecem discussões teóricas, os Encontros de Estudos, quanto aqueles que objetivam promover intersecções entre Psicologia Analítica e as mais diversas artes - os Encontros Criativos. Além deles, os eventos e seminários promovidos pelo grupo também foram amplamente difundidos nas redes sociais.

Nesses espaços, também, é apresentada a teoria da Psicologia Analítica/Complexa através de postagens curtas, de textos de autoria do grupo, imagens diversas, que apoiam as possibilidades de conversas com outras áreas do conhecimento, assim como funcionam como convite à leitura e a participação no grupo de estudos, independente da área de formação inicial.

Nesse sentido, o que foi percebido durante a experiência no projeto é que a divulgação das ações do grupo na página proporcionou um alcance significativo de pessoas, não apenas do curso e da área da Psicologia, mas ultrapassando as discussões dentro desse campo, motivando a comunidade externa a participar ativamente e até mesmo a fazer parte do GEPAN. Sendo observado um crescimento especificamente durante o processo de realização dessas ações, agregando seguidores e novos colaboradores.

Revista Extensão \& Cidadania, v. 9, n. 16, p. 7-20, jul./dez. 2021.

ISSN 2319-0566 DOI: 10.22481/recuesb.v9i16.8671 
Eventos, apresentações e interdisciplinaridade

As vivências no grupo possibilitaram ainda a produção de resumos para submissão em evento, uma possibilidade que reforça ainda mais o caráter de extensão do projeto. Foram apresentados quatro trabalhos no $9^{\circ}$ Congresso Brasileiro de Extensão Universitária: Redes para Promover e Defender os Direitos Humanos (CBEU), da Universidade Federal de Minas Gerais (UFMG), sendo eles: "Estudos de Psicologia Analítica: uma experiência de ensino e extensão"; "Encontros Criativos: sessões comentadas na perspectiva da psicologia analítica"; "Encontro Criativo "Aspectos simbólicos no filme Coringa"; e "A importância das redes sociais para o projeto de extensão Estudos em Psicologia Analítica”, em espaços virtuais no formato de redes de conversa, agrupados pela organização do evento em áreas e temáticas afins.

A participação nas redes de conversa do CBEU com a apresentação dos trabalhos reflete resultados de um processo muito significativo construído em grupo, que, ao se abrir a uma comunidade acadêmica mais ampla propicia ricas trocas de experiência. Foi possível entrar em contato com uma gama de trabalhos realizados em caráter de extensão, de diversas universidades e regiões do país, em e para comunidades diferentes.

Somado a essas possibilidades de socialização de produções vinculadas ao grupo, apresenta-se, como exemplo, uma das ações realizadas, o minicurso Arquétipos Sem Fim: Os perpétuos e os conceitos de Gaiman, sendo realizado no contexto de pandemia e sendo assim de forma virtual e gratuita, como todas as outras ações do grupo. $\mathrm{O}$ minicurso foi conduzido pelo Professor Ms. Glaudiney Moreira Mendonça Júnior, da Universidade Federal do Ceará (UFC) e do Grupo Paideia - apresentado em breve nesse texto, através das plataformas Google Meet e YouTube. Sobre a realização do minicurso, alguns pontos são abordados, a proposta de diferentes áreas, estabelecimento de parceria com outros grupos e entidades estudantis e a abrangência nacional, possibilitada pelo online.

A proposta inicial do minicurso está compreendida na aproximação da Psicologia Analítica/Complexa, de Carl Gustav Jung, foco primeiro do grupo, e a relação de seus constructos com a literatura de Neil Gaiman, especificamente sobre a série Sandman, da qual pertencem os 7 personagens discutidos na ação. Essa abordagem pode ser entendida como eficiente, uma vez que tanto o público interessado na Psicologia Analítica, quanto leitores e leitoras do trabalho de Gaiman, e demais interessados nas ampliações realizadas pelo condutor do encontro, puderam estar presentes. Destaca-se a importância da divulgação online nas redes

Revista Extensão \& Cidadania, v. 9, n. 16, p. 7-20, jul./dez. 2021.

ISSN 2319-0566 DOI: 10.22481/recuesb.v9i16.8671 
próprias do GEPAN, como em grupos de interessados na literatura citada. Esse procedimento é comum nas ações extensionistas pelos objetivos da interdisciplinaridade, como forma de ampliar discussões e contribuir para o olhar de estudos.

A referida realização teve dois principais parceiros, o Grupo Paideia vinculado à Universidade Federal do Ceará (UFC), mais especificamente ao curso de Letras, que se propôs a discutir diversos temas como mitologias, mitologia comparada, contos de fada e temáticas afins. O grupo é formado por diversos profissionais de Letras, História, Ciências da Computação entre outros, e promovem cursos, eventos e especializações. Uma outra parceria, a nível local, o Centro Acadêmico de Psicologia, que trabalhou na articulação e divulgação junto ao GEPAN, para o corpo estudantil e outros centros acadêmicos diversos, cujas parcerias já haviam sido realizadas.

Pensando nesses movimentos de produção, divulgação e estabelecimento de parcerias diversas, assim como a realização da ação em meios online, apresenta-se sua amplitude a seguir, com dados oriundos do processo de inscrição e de lista de presença, utilizada para certificação de ouvintes e demais participantes, junto à Gerência de Extensão e Assuntos Culturais (GEAC), da UESB. Desta maneira, para apresentar de forma descritiva, temos os seguintes dados: 749 inscritos no evento durante o período de divulgação, encerrado um dia antes da realização do minicurso; 370 participantes inscritos que assinaram a lista de presença; amplitude nacional, sendo apresentada pelo gráfico a seguir:

\section{Gráfico 1 - Porcentagem de inscritos no minicurso Arquétipos Sem Fim, por região do Brasil $(\mathbf{n}=370)$}

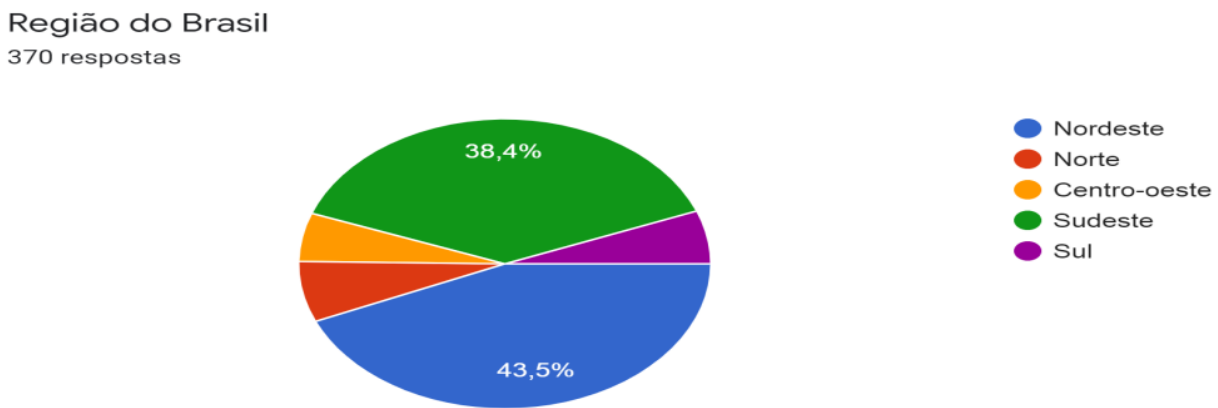

Fonte: Elaborado pelos autores.

Revista Extensão \& Cidadania, v. 9, n. 16, p. 7-20, jul./dez. 2021.

ISSN 2319-0566 DOI: 10.22481/recuesb.v9i16.8671 
A representação quantitativa da distribuição espacial (regiões do Brasil) dos ouvintes do minicurso torna possível uma visualização clara: do número total de participantes $(n=370)$, 43,5\% ( $\mathrm{n}=161)$ declararam ser da região nordeste, seguido por 38,4\% ( $\mathrm{n}=142)$ da região sudeste, tendo as regiões norte, sul e centro-oeste, respectivamente 6,8\% ( $\mathrm{n}=25), 5,9 \%(\mathrm{n}=22)$ e 5,4\% (n=20). Cabe ressaltar que com a transmissão também feita pela plataforma YouTube, ficando salva, soma até o momento 1,552 visualizações, daqueles inscritos que quiseram rever ou dos demais interessados. Sendo assim, apesar de a região com maior presença ser o Nordeste, local onde os grupos se situam fisicamente, com a possibilidade da realização online, as ações do GEPAN podem ser ampliadas para as outras 4 regiões do país, tendo em vista os processos de divulgação já citados. Ressaltando, portanto, a importância das parcerias com grupos, entidades e também com o viés interdisciplinar.

\section{Conclusão}

As ações realizadas pelo projeto não seriam possíveis sem a iniciativa do Grupo de Estudos em Psicologia Analítica, o qual tem se implicado em tornar presentes as discussões de um campo que foi por muito tempo restrito à academia, além das parcerias com outros grupos e instituições estudantis que aceitaram o desafio de somar e trazer novas ideias aos eventos. Trazer tais debates à extensão, foi uma forma também de reforçar o papel imprescindível da cultura na educação. Além disso, entende-se também que a Pró-Reitoria de Extensão e Assuntos Comunitários (PROEX) adota uma política que democratiza a realização de projetos das mais diversas áreas, de importância salutar à produção de conhecimento na universidade pública, a partir da qual foi possível financiar o presente trabalho com duas bolsas para discente extensionista em 2019, e mais duas em 2020.

Retoma-se finalmente a importância das ações extensionistas que funcionaram como catárticas à produção de diferentes ferramentas de aproximação da comunidade externa e de construção coletiva e multidimensional dos saberes, não restringindo-a apenas ao espaço da Psicologia, mas mediando através das artes e tecnologias de comunicação, os mais diversos temas. Em ampliação ao pensamento de Moran (1995) sobre as tecnologias e o encantamento na escola, conclui-se que o encantamento está não nas ferramentas tecnológicas ou nas proposições teóricas, mas na capacidade de nos tornarmos pessoas plenas: em termos junguianos, de nos tornarmos conscientes de nós mesmos em nosso processo de individuação.

Revista Extensão \& Cidadania, v. 9, n. 16, p. 7-20, jul./dez. 2021.

ISSN 2319-0566 DOI: 10.22481/recuesb.v9i16.8671 
E só com esse componente humano, ético, é possível utilizar dos saberes de modo a construir mundos plurais.

\section{Referências}

A FACE do outro. Direção e produção de Hiroshi Teshigahara. Elenco: Tatsuya Nakadai, Machiko Kyō, Kyōko Kishida e outros. Roteiro: Kōbō Abe. Tóquio: Teshigahara Tokyo Co., 1966. 1 DVD (121 min).

A OSTRA e o vento. Direção de Walter Lima Jr. Elenco: Leandra Leal, Lima Duarte, Fernando Torres, Castrinho, Floriano Peixoto, Débora Bloch e outros. Roteiro: Walter Lima Jr., Flávio Ramos Tambellini e Moacir C. Lopes. Brasil: Ravina Filmes, 1997. 1 DVD (118 $\min )$.

BABADOOK. Direção de Jennifer Kent. Produção de Kristina Ceyton. Elenco: Essie Davis, Noah Wiseman, Hayley McElhinney e outros. Roteiro: Jennifer Kent. Austrália:

Entertainment One/Umbrella, 2014. 1 DVD (94 min).

CARL GUSTAV JUNG: Questão do coração. Direção de Mark Whitfield. Roteiro: Susanne Wagner. Estados Unidos: Image Entertainment, 1983. 1 DVD (107 min).

CORINGA. Direção de Todd Phillips. Produção de Todd Phillips, Bradley Cooper e Emma Koskoff. Elenco: Joaquin Phoenix, Robert De Niro, Zazie Beetz e outros. Estados Unidos: Warner Bros. Pictures/DC Films, 2019. 1 DVD (122 min).

FRANZ, Marie-Louise von. A interpretação dos contos de fadas. São Paulo: Paulus, 1999.

FÓRUM DE PRÓ-REITORES DE EXTENSÃO DAS UNIVERSIDADES PÚBLICAS BRASILEIRAS. Plano Nacional de Extensão Universitária. Manaus: FORPROEX, 2012. Extensão Universitária, v. 1.

GAIMAN, Neil. O oceano no fim do caminho. Trad. Renata Pettengill. Rio de Janeiro: Intrínseca, 2013.

GUARDIÃO dos sonhos. Produção de Ron McLeod e Matthew O'connor. Direção de Steven Barron. Canadá: Hallmark, 2003. 1 DVD (180 min).

JUNG, Carl Gustav. A prática da psicoterapia: contribuições ao problema da psicoterapia e à psicologia da transferência. Petrópolis: Vozes, 1985. (Obras completas de C. G. Jung v. $\mathrm{XVI} / 1)$

JUNG, Carl Gustav. Presente e futuro: civilização e mudança (parte 1). Petrópolis: Vozes, 2011. (Obras completas de C. G. Jung v. X/1)

Revista Extensão \& Cidadania, v. 9, n. 16, p. 7-20, jul./dez. 2021.

ISSN 2319-0566 DOI: 10.22481/recuesb.v9i16.8671 
JUNG, Carl Gustav. Da formação da personalidade. In: JUNG. C. G. O desenvolvimento da personalidade. Petrópolis: Vozes, 2011. p. 148-166. (Obras completas de C. G. Jung v. XVII)

JUNG, Carl Gustav. Resposta a Martin Buber. In: JUNG. C. G. Escritos diversos.

Petrópolis: Vozes, 2012. p. 113-150. (Obras completas de C. G. Jung v. XI/6)

JUNG, Carl Gustav. Aion: estudos sobre o simbolismo do si-mesmo. Petrópolis: Vozes, 1990. (Obras completas de C. G. Jung v. IX/2)

JUNG, Carl Gustav. Psicologia do inconsciente. Petrópolis: Vozes, 2011. (Obras completas de C. G. Jung v. VII/1)

JUNG, Carl Gustav. O Eu e o inconsciente. Petrópolis: Vozes, 2008. (Obras completas de C. G. Jung v. VII/2)

JUNG, Carl Gustav. Os arquétipos e o inconsciente coletivo. Petrópolis: Vozes, 2000.

(Obras completas de C. G. Jung v. IX/1)

JUNG, Carl Gustav. Tipos psicológicos. Petrópolis: Vozes, 1991. (Obras completas de C. G. Jung v. VI)

JUNG, Carl Gustav. Fundamentos de psicologia analítica. Petrópolis: Vozes, 1985. (Obras completas de C. G. Jung v. XVIII/1)

JUNG, Carl Gustav. Chegando ao inconsciente. In: JUNG. C. G. O homem e seus símbolos. Rio de Janeiro: Novas Fronteiras, 1964.

KILL BILL, Vol. 1. Direção e produção de Quentin Tarantino. Elenco: Uma Thurman, Lucy Liu, Vivica A. Fox e outros. Estados Unidos: Miramax Films, 2003. 1 DVD (111 min).

MONTEIRO, Dulcinea da Mata Ribeiro. Jung e o cinema: psicologia analítica através de filmes. 2. ed. rev. e amp. Curitiba: Juruá, 2013.

MORAN, José Manuel. Novas tecnologias e o reencantamento do mundo. Tecnologia Educacional, Rio de Janeiro, v. 23, n.126, p. 24-26, set./out. 1995. Disponível em: http://www.eca.usp.br/prof/moran/site/textos/tecnologias_eduacacao/novtec.pdf. Acesso em: 5 maio 2021.

ODAJNYK, Volodymyr Walter. Jung and politics: the political and social ideas of C. G. Jung. Lincoln: Authors Choice Press, 2007.

PEIXE GRANDE. Direção de Tim Burton. Produção de Richard D. Zanuck, Bruce Cohen e Dan Jinks. Elenco: Ewan McGregor, Albert Finney, Billy Crudup e outros. Roteiro: John August. Estados Unidos: Sony Pictures, 2003. 1 DVD (125 min).

Revista Extensão \& Cidadania, v. 9, n. 16, p. 7-20, jul./dez. 2021.

ISSN 2319-0566 DOI: 10.22481/recuesb.v9i16.8671 
PINK FLOYD The Wall. Produção de Allan Marshall. Direção de Alan Parker e Roger Waters. Elenco: Bob Geldof, James Laurenson, Eleanor David e outros. Roteiro: Roger Waters. Reino Unido: MGM/UA Entertainment, 1982. 1 DVD (95 min).

SETE MINUTOS depois da meia noite. Direção de Juan Antonio García Banoya. Elenco: Sigourney Weaver, Felicity Jones, Toby Kebbell e outros. Espanha: Universal Pictures, 2016. 1 DVD (108 min).

SHAMDASANI, Sonu. Jung e a construção da psicologia moderna: o sonho de uma ciência. Trad. Maria Silvia Mourão Netto. Aparecida: Ideias \& Letras, 2011.Edição digital. Disponível em:

file://C:/Users/User/Downloads/Jung\%20e\%20a\%20construcao\%20da\%20psicologia\%20mo derna-Sonu-Shamdasani.pdf. Acesso em: 10 ago. 2021.

SILVEIRA, Nise da. Jung: vida e obra. Rio de Janeiro: Paz e Terra, 1981.

Recebido: 14.05.2021

Aceito: 04.08.2021

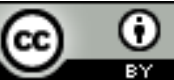

This work is licensed under a Creative Commons Attribution 4.0 International License.

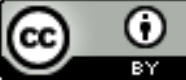

Este trabalho está licenciado com uma Licença Creative Commons - Atribuição 4.0

Revista Extensão \& Cidadania, v. 9, n. 16, p. 7-20, jul./dez. 2021.

ISSN 2319-0566 DOI: 10.22481/recuesb.v9i16.8671 